\section{BRAZIULIAN JOURNAL \\ OF MEDICAL AND BIOLOGICAL RESF.ARCH}

www.bjournal.com.br
ISSN 0100-879X

Volume 42 (12) 1119-1247 December 2009

BIOMEDICAL SCIENCES

AND

CLINICAL INVESTIGATION

Braz J Med Biol Res, December 2009, Volume 42(12) 1236-1241

C-reactive protein in acute coronary syndrome: association with 3-year outcomes

B.D. Schaan, L.C. Pellanda, P.T. Maciel, E.R. Duarte and V.L. Portal

The Brazilian Journal of Medical and Biological Research is partially financed by
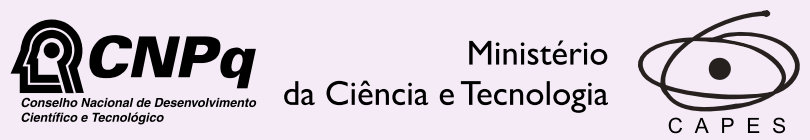

Ministério da Educação

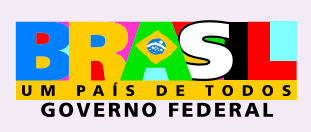

DFAPESP

Institutional Sponsors 


\title{
C-reactive protein in acute coronary syndrome: association with 3-year outcomes
}

\author{
B.D. Schaan ${ }^{1,2}$, L.C. Pellanda ${ }^{1,3}$, P.T. Maciel $^{1,4}$, E.R. Duarte ${ }^{1}$ and V.L. Portal ${ }^{1}$ \\ ${ }^{1}$ Instituto de Cardiologia do Rio Grande do Sul, Fundação Universitária de Cardiologia, Porto Alegre, RS, Brasil \\ 2Serviço de Endocrinologia, Hospital de Clínicas de Porto Alegre, \\ Departamento de Medicina Interna, Universidade Federal do Rio Grande do Sul, Porto Alegre, RS, Brasil \\ ${ }^{3}$ Universidade Federal de Ciências da Saúde, Porto Alegre, RS, Brasil \\ ${ }^{4}$ Mãe de Deus Hospital, Porto Alegre, RS, Brasil
}

\begin{abstract}
Inflammatory markers have been associated with clinical outcome in patients with acute coronary syndrome (ACS). The present study evaluated the role of high-sensitivity C-reactive protein (CRP) measurements as a predictor of late cardiovascular outcomes after ACS. One hundred and ninety-nine ACS patients in a Coronary Care Unit from March to November 2002 were included and were reassessed clinically after $\sim 3$ years. Clinical variables and CRP levels were evaluated as predictors of major cardiovascular events (MACE, defined as the occurrence of cardiac death, ischemic stroke or myocardial infarction) and mortality. Statistical analyses included Cox multivariable analysis and survival curves (Kaplan-Meier). Of the 199 patients, 11 died within 1 month (5.5\%). Of the 188 remaining patients, 22 died after a mean follow-up of $2.9 \pm 0.5$ years. Baseline CRP levels for patients with MACE $(\mathrm{N}=57)$ were significantly higher than those of patients with no events (median $=0.67 \mathrm{mg} / \mathrm{L} ; 25 \mathrm{th}-75 \mathrm{th}$ percentiles $=0.32$ and $1.99 \mathrm{mg} / \mathrm{L}$ vs median $=0.45 \mathrm{mg} / \mathrm{L} ; 25$ th -75 th percentiles $=0.24$ and $0.83 \mathrm{mg} / \mathrm{L} ; \mathrm{P}<0.001)$. Patients with CRP levels $>3 \mathrm{mg} / \mathrm{L}$ had a significantly lower survival than the other two groups $(1-3$ and $<1 \mathrm{mg} / \mathrm{L} ; \mathrm{P}=0.001$, log-rank test). The odds ratio for MACE was 7.41 (2.03-27.09) for patients with CRP $>3 \mathrm{mg} / \mathrm{L}$ compared with those with CRP $<1 \mathrm{mg} / \mathrm{L}$. For death by any cause, the hazard ratio was 4.58 (1.93-10.86). High CRP levels predicted worse long-term outcomes (MACE and death by any cause) in patients with ACS.
\end{abstract}

Key words: Acute coronary syndromes; Inflammatory markers; C-reactive protein; Major cardiovascular events; Mortality

\section{Introduction}

Atherosclerosis has been shown to be an inflammatory disease. Inflammatory cell infiltrates may be found in chronic atherosclerosis, and there is evidence of immune activation of atherosclerotic plaques (1). Inflammatory markers that have been evaluated in clinical studies include $\mathrm{C}$-reactive protein (CRP) (2), leukocyte count (3), interleukin-6 and -18 (4), and fibrinogen (5).

C-reactive protein is the best characterized and most widely studied marker of plaque progression and cardiovascular disease risk, reflecting the underlying inflammatory process $(1,2,6,7)$ and also playing a role in the atherosclerotic process by interacting directly with atherosclerotic vessels, activating the complement system and promoting inflammation and thrombosis (8). Elevated CRP has been shown to be associated with increased mortality in several settings $(9,10)$, including acute coronary syndrome (11-13), both on a short- (14) and long-term basis (15). However, there still is controversy about the clinical use of CRP in this setting. A recent large prospective study did not support the incremental value of measuring CRP in acute coronary syndrome (16). Considering the potential benefits of treating high levels of CRP with pharmacological agents for the prevention of cardiovascular events in apparently healthy individuals with elevated CRP (17), the identification of high risk subgroups is of paramount importance in planning effective therapeutic strategies.

Thus, the goal of the present study was to evaluate the association between the inflammatory marker CRP at hospitalization for acute coronary syndrome and late cardiovascular outcomes ( $\sim 3$ years).

\section{Patients and Methods}

In this cohort study, we prospectively included 199 pa-

Correspondence: B.D. Schaan, Unidade de Pesquisa do IC/FUC, Av. Princesa Isabel, 370, 90620-001 Porto Alegre, RS, Brasil.

Fax: +55-51-3219-2802. E-mail: bschaan.pesquisa@cardiologia.org.br or beatrizschaan@gmail.com

Received April 27, 2009. Accepted October 27, 2009. Available online November 9, 2009. Published December 4, 2009. 
tients with clinical presentation of acute coronary syndrome admitted to the Coronary Intensive Care Unit of Instituto de Cardiologia do Rio Grande do Sul, Fundação Universitária de Cardiologia (IC/FUC) from March to November 2002. The original inclusion criteria were: 1) a recent (within 72 $\mathrm{h}$ from the onset of symptoms) history of unstable angina with ST depression of at least $1 \mathrm{~mm}$ or T-wave inversion with normal enzymes; 2) acute myocardial infarction without ST elevation: chest pain suggestive of acute myocardial infarction with no ST elevation and abnormal enzymes, and 3) acute myocardial infarction with ST elevation: chest pain suggestive of acute myocardial infarction with ST elevation of at least $2 \mathrm{~mm}$ in two different leads, and abnormal enzymes (creatine kinase (CK) and CK-MB). Patients were followed at approximately 6-month intervals, and a final long-term follow-up evaluation was performed from June to September 2005.

Detailed methods have been previously published (14). Briefly, the initial evaluation included medical history (family history of coronary artery disease, systemic arterial hypertension, smoking, diabetes mellitus, dyslipidemia, sedentarism), physical examination, and laboratory tests at admission (after a 12-h fast). These patients had previously signed a letter of consent approved by the Institutional Research Ethics Committee. Patients presenting more than $10 \mathrm{~h}$ after the first symptoms, without the 12-h fast, and with chronic inflammatory conditions or neoplastic disease were excluded.

The patients were contacted by letter or telephone and a new clinical evaluation $\sim 3$ years after the initial clinical presentation of the acute coronary syndrome was scheduled. Evaluation included history of complications/hospitalizations after discharge and current symptoms. Patients who responded to the request and came to the Institution were submitted to a questionnaire and to physical examination. The patients who could not come for evaluation answered the questions by telephone. In case of death, family members, local health/social services and the State Department of Health database were contacted.

The main outcomes considered were death and major cardiovascular events (MACE), defined as the occurrence of cardiac death, ischemic stroke, myocardial infarction (defined according to the criteria of the American College of Cardiology) (18), or the need for a percutaneous or surgical revascularization. These outcomes were analyzed throughout the follow-up period.

Of the 199 patients selected, 11 (5.5\%) died within 1 month. Regarding the 188 remaining patients, after a mean follow-up of $2.9 \pm 0.5$ years, information was obtained for 142 (75.5\%); 91 (64.1\%) patients came to the hospital, and information was obtained for $51(35.9 \%)$ by telephone from close relatives, the patient himself or from the hospital records. Of these 142 patients, 22 had died. Forty-six patients were lost to follow-up. In order to evaluate the importance of losing $23.1 \%$ of the patients (46 of 199), the
46 patients lost were compared to the 153 for whom current data were obtained. The clinical characteristics of the two groups were similar: baseline glycemia, total cholesterol, triglycerides, HDL-C, LDL-C, fibrinogen, percentage of males, smoking, sedentarism, and overweight. However, age was lower (57.4 \pm 12 vs $62.4 \pm 12$ years, $P=0.009)$, and CRP was higher (median $=0.95 \mathrm{mg} / \mathrm{L} ; 25$ th and 75 th percentiles $=0.31$ and $2.01 \mathrm{mg} / \mathrm{L}$ vs median $=0.51 \mathrm{mg} / \mathrm{L}$; 25th and 75th percentiles $=0.25$ and $1.04 \mathrm{mg} / \mathrm{L} ; \mathrm{P}=0.03$ ) among the 46 lost patients.

\section{Laboratory tests}

Cholesterol and triglycerides were analyzed using an automated enzymatic kit (Boehringer Mannheim Diagnostics, Germany), HDL-C was determined with a single enzymatic kit using heparin-2M Mncl2, and LDL-C was calculated using the Friedwald formula. Glycemia was evaluated with an automated enzymatic kit (Merck Diagnostics, Germany) using a Hitachi biochemical analyzer, model 902, Japan). Fibrinogen was evaluated by an automated coagulopathy method using the CA 500 equipment (Sysmex, Japan). Ultra-sensitive CRP was determined by nephelometry using the BN100 equipment (Dade Behring, Inc., Germany).

\section{Statistical analysis}

Data are reported as means and standard deviations or proportions. C-reactive protein was evaluated as a categorized variable according to cut-off points of $<1,1-3$, and $>3$ $\mathrm{mg} / \mathrm{L}$. ANOVA and the Pearson chi-square test were used for comparison of baseline characteristics of the patients according to CRP levels. The Mann-Whitney test, the Cox multivariable analysis model and logistic regression were used to determine differences in CRP levels between patients with events and patients without events. Survival curves were constructed by the Kaplan-Meier method according to the different categories of CRP, with the curves being compared by the log-rank test. AP $<0.05$ value was considered to be statistically significant.

\section{Results}

The mean age of the 199 patients initially studied was $61.1 \pm 12$ years and $65.8 \%$ were men. The presentation of acute ischemic syndrome was acute myocardial infarction with ST-segment elevation in $71 \%$ (142), acute myocardial infarction without ST-segment elevation in 12\% (23) and unstable angina in 17\% (34). The characteristics of these patients according to CRP levels are presented in Table 1. Patients with higher CRP levels were older (64.5 \pm 15.0 years) than the two other groups with levels $<1$ and $1-3 \mathrm{mg} / \mathrm{L}$ $(60.5 \pm 10.8$ and $60.9 \pm 14.2$ years, respectively), but otherwise quite similar to those with lower levels (Table 1).

The baseline CRP levels of the patients who developed MACE $(N=57)$ were significantly higher than those of patients who did not (median $=0.67 \mathrm{mg} / \mathrm{L} ; 25$ th and 75 th 
percentiles $=0.32$ and $1.99 \mathrm{mg} / \mathrm{L}$ vs median $=0.45 \mathrm{mg} / \mathrm{L}$; 25th and 75 th percentiles $=0.24$ and $0.83 \mathrm{mg} / \mathrm{L} ; \mathrm{P}<0.001)$. Similarly, the baseline CRP levels of the patients who died $(\mathrm{N}=33)$ were significantly higher than those of patients who survived $($ median $=0.79 \mathrm{mg} / \mathrm{L} ; 25$ th and 75 th percentiles $=0.26$ and $3.01 \mathrm{mg} / \mathrm{L}$ vs median $=0.48 \mathrm{mg} / \mathrm{L} ; 25 \mathrm{th}$ and 75th percentiles $=0.25$ and $0.85 \mathrm{mg} / \mathrm{L} ; \mathrm{P}=0.008)$. CRP was evaluated as a predictive factor for death and MACE, controlling for other possible confounding factors such as thrombolysis in myocardial infarction (TIMI) risk (19) and systolic blood pressure. Table 2 presents the hazard ratio for death and the odds ratio for MACE for the three CRP groups, adjusted for TIMI risk and systolic blood pressure. Both endpoints could be predicted by progressively higher CRP levels ( $P=0.003$ for death and $P=0.010$ for MACE), independently of the variables cited above (Table 2). The

Table 1. Baseline characteristics of the patients according to C-reactive protein levels.

\begin{tabular}{lcrc}
\hline Variables & $<1 \mathrm{mg} / \mathrm{L}$ & $1-3 \mathrm{mg} / \mathrm{L}$ & $>3 \mathrm{mg} / \mathrm{L}$ \\
\hline Age (years) & $60.5 \pm 10.8$ & $60.9 \pm 14.2$ & $64.5 \pm 15.0^{*}$ \\
Systolic blood pressure (mmHg) & $125.4 \pm 23.7$ & $131.8 \pm 22.9$ & $116.8 \pm 24.0$ \\
Fibrinogen (mg/dL) & $244.6 \pm 62.4$ & $259.0 \pm 80.1$ & $282.7 \pm 93.9$ \\
Total cholesterol (mg/dL) & $195.8 \pm 44.8$ & $187.5 \pm 45.6$ & $177.5 \pm 44.7$ \\
Glycemia (mg/dL) & $144.3 \pm 71.4$ & $138.4 \pm 45.8$ & $148.3 \pm 72.8$ \\
Male gender & $86(64.2 \%)$ & $30(76.9 \%)$ & $14(66.7 \%)$ \\
Hypertension & $78(58.2 \%)$ & $23(59.9 \%)$ & $16(76.2 \%)$ \\
Diabetes mellitus & $29(21.6 \%)$ & $6(15.4 \%)$ & $5(23.8 \%)$ \\
Dyslipidemia & $92(69.2 \%)$ & $27(71.1 \%)$ & $10(47.6 \%)$ \\
Smoking & $67(50.4 \%)$ & $16(42.1 \%)$ & $5(23.8 \%)$ \\
Sedentarism & $69(51.9 \%)$ & $22(57.9 \%)$ & $13(61.9 \%)$ \\
ACE inhibitor use & $38(28.6 \%)$ & $14(35.9 \%)$ & $7(33.3 \%)$ \\
Statin use & $15(11.2 \%)$ & $4(10.3 \%)$ & $4(19.0 \%)$ \\
Beta-blocker use & $45(33.6 \%)$ & $8(20.5 \%)$ & $7(33.3 \%)$ \\
Antiplatelet therapy & $56(41.8 \%)$ & $15(38.5 \%)$ & $9(42.9 \%)$ \\
Unstable angina & $21(15.7 \%)$ & $10(25.6 \%)$ & $5(23.8 \%)$ \\
MI with ST elevation & $101(75.4 \%)$ & $21(53.8 \%)$ & $15(71.4 \%)$ \\
MI without ST elevation & $12(9.0 \%)$ & $8(20.5 \%)$ & $1(4.8 \%)$ \\
Primary PCl & $86(81.9 \%)$ & $16(64.0 \%)$ & $10(76.9 \%)$ \\
TIMI risk & & & \\
0-2 & $14(10.4 \%)$ & $6(15.4 \%)$ & $1(4.8 \%)$ \\
3-4 & $75(56 \%)$ & $27(69.2 \%)$ & $12(57.1 \%)$ \\
5-7 & $45(33.6 \%)$ & $6(15.4 \%)$ & $8(38.1 \%)$ \\
\hline
\end{tabular}

Data are reported as means $\pm S D$ or number with percent in parentheses. $A C E=$ angiotension-converting enzyme: $\mathrm{MI}=$ myocardial infarction; $\mathrm{PCl}=$ percutaneous coronary intervention. TIMI $=$ thrombolysis in myocardial infarction. ${ }^{*} \mathrm{P}<0.05 \mathrm{com}$ pared to other groups (ANOVA).

Table 2. Hazard ratio, odds ratio and $95 \%$ confidence intervals for MACE and deaths for the three CRP groups, adjusted for TIMI risk score and systolic blood pressure.

\begin{tabular}{lcccc}
\hline Outcome & CRP $<1 \mathrm{mg} / \mathrm{L}$ & CRP 1-3 mg/L & CRP $>3 \mathrm{mg} / \mathrm{L}$ & $\mathrm{P}$ for trend \\
\hline Death $^{\mathrm{a}}$ & 1.0 & $1.57(0.57-4.34)$ & $4.58(1.93-10.86)$ & 0.003 \\
MACE $^{\mathrm{b}}$ & 1.0 & $1.27(0.47-3.49)$ & $7.41(2.03-27.09)$ & 0.010 \\
\hline
\end{tabular}

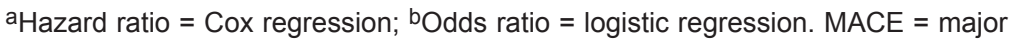
cardiovascular events; CRP = C-reactive protein; TIMI = thrombolysis in myocardial infarction. 


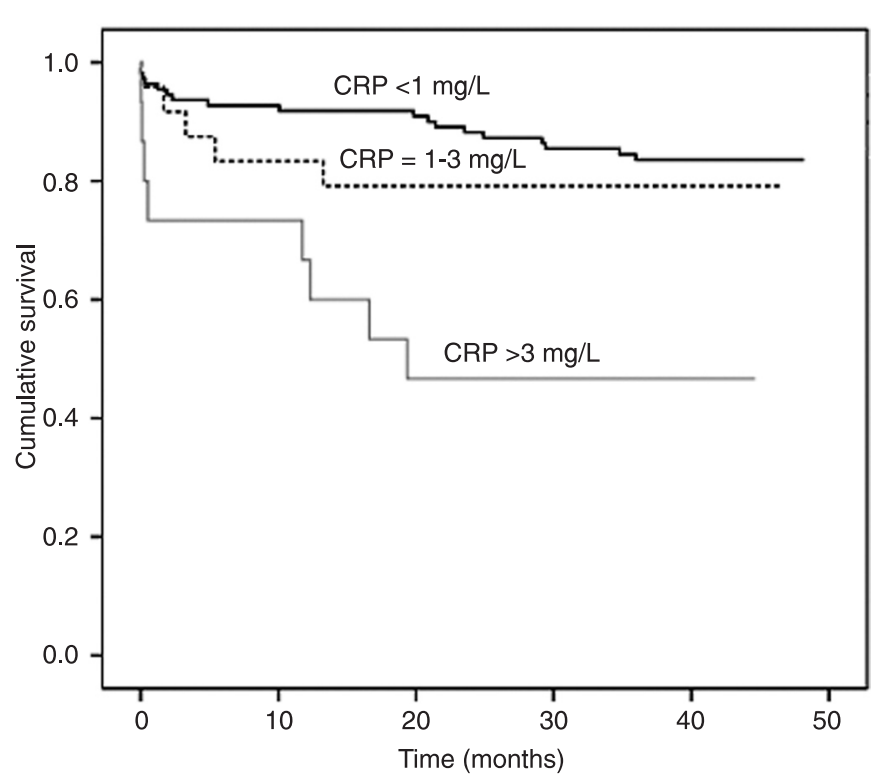

Figure 1. Kaplan Meier survival curve for patients in the three C-reactive protein (CRP) groups $(<1,1-3$ and $>3 \mathrm{mg} / \mathrm{L})$.

inclusion of CRP (comparison of C-statistics between a model without CRP and a model with CRP) effectively added predictive accuracy to the multivariable model, as shown by the statistical comparison of the two models $(P$ $=0.007$ for death, prediction of 62 vs $66.7 \%, P=0.005$ for MACE). We analyzed the group of ST-elevation myocardial infarction separately and the results were similar to those observed in the total sample (63.6 vs $72 \%$ ).

Figure 1 shows the Kaplan Meier survival curve for patients in the three CRP groups. Patients with CRP levels $>3 \mathrm{mg} / \mathrm{L}$ showed a significantly $(P=0.001)$ lower survival than the other two groups $(1-3$ and $<1 \mathrm{mg} / \mathrm{L})$, as illustrated in Figure 1.

\section{Discussion}

In this cohort study, high CRP levels in acute coronary syndrome predicted worse long-term outcomes, as evaluated by larger number of deaths and MACE, confirming previous results obtained by our group during a short-term follow-up (higher number of in-hospital events 30 days after the acute coronary syndrome episode) (14).

The better understanding of the inflammatory nature of atherosclerosis has led to a search for potentially useful markers. Potential candidates include pro-inflammatory cytokines (interleukin-1, TNF-alpha, interleukin-6), adhesion molecules (ICAM-1, selectins) and hepatic acute phase reactants (CRP, amyloid-A). CRP, which has been classically used to describe acute reactions, is the biomarker with the largest body of evidence accumulated to date, although controversy still persists. It has been shown to have a longer half-life, more stable levels in blood and less circadian variability (20). Based on the results of several prospective epidemiological studies, CRP has emerged in recent years as an important prognostic marker, capable of providing useful information in a variety of clinical situations.

In acute coronary syndrome, CRP proved to be predictive of worse outcomes at hospitalization $(14,21)$ and at 14-day $(11,21), 30$-day $(14,22)$ and 5-month follow-ups (23). Fewer studies have described longer periods of follow-up, with discordant findings. A large prospective study that followed 1210 patients from 8 tertiary and secondary hospitals for 1 year, a shorter follow-up than studied here, recently showed that the modest predictive ability of CRP following admission for an acute coronary syndrome disappeared after adjustment for common clinical variables (16). However, other studies have reported different results. Mueller et al. (15) showed that CRP is a strong independent predictor of long-term mortality after non-ST acute coronary syndrome in a 20 -month follow-up. Lindahl et al. (24) showed that troponin T and CRP are strongly related to the long-term (37 months) risk of death from cardiac causes. Association with the development of heart failure and mortality in patients with acute myocardial infarction was reported also by Suleiman et al. (25), with CRP levels providing prognostic information beyond that provided by conventional risk factors in a mean follow-up of 23 months.

Our data, obtained for fewer patients, but with a 3-year follow-up period, agree with these studies, and thus add evidence to the hypothesis that CRP is an important prognostic marker in patients with acute coronary syndrome, and can be clinically useful to identify patients at a greater risk of short- and long-term events. In the present study, patients with CRP levels $>3 \mathrm{mg} / \mathrm{L}$ showed an almost 5 -fold increase in the risk of death compared to patients with lower levels, and a 7-fold increase in the risk of MACE. Although some investigators have reported a higher cut-off value for CRP (>10 mg/L) in patients with acute coronary syndrome as predictive of adverse outcomes $(15,26,27)$, others $(28,29)$ have used cut-off values similar to those chosen by us.

These findings open the possibility of exploring different interventions for lowering chronic inflammation in patients identified as belonging to high risk groups based on their inflammation status. For example, the use of aspirin in the Physician's Health Study significantly reduced the risk of acute myocardial infarction for patients belonging to the highest quartile of CRP, but not for those in the lowest quartile (30). Many recent studies have suggested that, in parallel to their lipid-lowering properties, statins may have also anti-inflammatory and anti-oxidant properties. Large randomized trials using aggressive lipid lowering with highdose statins have shown that statins may reduce CRP levels 
independently of lipid reduction (17).

Some limitations of our study deserve discussion. Being observational in nature, confounding, especially by variables such as age, smoking and drug use, cannot be ruled out as an explanation for the findings. To deal with this possibility, we included all the important variables in a multivariable regression model, which showed that CRP levels remained strongly and independently associated with events. Also, the confidence intervals obtained were relatively wide, possibly reflecting insufficient precision. However, the lower limits of confidence intervals are still clinically significant, which turns the results useful despite the wide intervals. Additionally, the possibility of type I error was very small in all analyses ( $P$ for trend). Residual confounding by variables not included in the model such as underlying subclinical conditions should also be considered. Sample size may be insufficient for subgroup analysis that would be important in this setting. For example, the TIMI risk score is different for non-ST elevation acute coronary syndrome and ST elevation myocardial infarction but, since

\section{References}

1. Libby P. Inflammation in atherosclerosis. Nature 2002; 420: 868-874.

2. Ridker PM, Buring JE, Cook NR, Rifai N. C-reactive protein, the metabolic syndrome, and risk of incident cardiovascular events: an 8-year follow-up of 14,719 initially healthy American women. Circulation 2003; 107: 391-397.

3. Sanchez PL, Morinigo JL, Pabon P, Martin F, Piedra I, Palacios IF, et al. Prognostic relations between inflammatory markers and mortality in diabetic patients with non-ST elevation acute coronary syndrome. Heart 2004; 90: 264-269.

4. Souza JR, Oliveira RT, Blotta MH, Coelho OR. Serum levels of interleukin-6 (IL-6), interleukin-18 (IL-18) and C-reactive protein (CRP) in patients with type-2 diabetes and acute coronary syndrome without ST-segment elevation. Arq Bras Cardiol 2008; 90: 86-90.

5. Kannel WB. Overview of hemostatic factors involved in atherosclerotic cardiovascular disease. Lipids 2005; 40: 1215-1220.

6. Berk BC, Weintraub WS, Alexander RW. Elevation of Creactive protein in "active" coronary artery disease. Am J Cardiol 1990; 65: 168-172.

7. Ridker PM. Clinical application of C-reactive protein for cardiovascular disease detection and prevention. Circulation 2003; 107: 363-369.

8. Lagrand WK, Visser CA, Hermens WT, Niessen HW, Verheugt FW, Wolbink GJ, et al. C-reactive protein as a cardiovascular risk factor: more than an epiphenomenon? Circulation 1999; 100: 96-102.

9. Kompoti M, Drimis S, Papadaki A, Kotsomytis K, Poulopoulou C, Gianneli D, et al. Serum C-reactive protein at admission predicts in-hospital mortality in medical patients. Eur $J$ Intern Med 2008; 19: 261-265.

10. Mueller C, Laule-Kilian K, Christ A, Brunner-La Rocca HP, Perruchoud AP. Inflammation and long-term mortality in acute congestive heart failure. Am Heart J 2006; 151: 845- there were only 57 patients with non-ST elevation acute coronary syndrome, separate analysis with this group resulted in wide confidence intervals. The final sample may not represent all the individuals evaluated at baseline, but we made all possible efforts to locate these patients and to obtain vital status information for those who were lost to follow-up. Additionally, we showed that the individuals lost to follow-up were similar to those in the final sample regarding clinical and laboratory variables.

CRP levels adequately predicted increased long-term risk in a population of patients initially evaluated at admission due to acute coronary syndrome. This association was observed independently of lipid levels, and thus may add information for risk stratifying and planning of effective interventions in this group of patients.

\section{Acknowledgments}

Research supported by grants from FAPICC and FAPERGS.
850.

11. Morrow DA, Rifai N, Antman EM, Weiner DL, McCabe CH, Cannon CP, et al. C-reactive protein is a potent predictor of mortality independently of and in combination with troponin T in acute coronary syndromes: a TIMI 11A substudy. Thrombolysis in Myocardial Infarction. J Am Coll Cardiol 1998; 31 : 1460-1465.

12. Kim H, Yang DH, Park Y, Han J, Lee H, Kang H, et al. Incremental prognostic value of $\mathrm{C}$-reactive protein and $\mathrm{N}$-terminal proB-type natriuretic peptide in acute coronary syndrome. Circ J 2006; 70: 1379-1384.

13. Sabatine MS, Morrow DA, Jablonski KA, Rice MM, Warnica JW, Domanski MJ, et al. Prognostic significance of the Centers for Disease Control/American Heart Association highsensitivity C-reactive protein cut points for cardiovascular and other outcomes in patients with stable coronary artery disease. Circulation 2007; 115: 1528-1536.

14. Duarte ER, Pellanda LC, Portal VL. [Inflammatory, lipid, and metabolic profile in acute ischemic syndrome: correlation with hospital and posthospital events]. Arq Bras Cardiol 2005; 84: 122-129.

15. Mueller C, Buettner HJ, Hodgson JM, Marsch S, Perruchoud AP, Roskamm H, et al. Inflammation and long-term mortality after non-ST elevation acute coronary syndrome treated with a very early invasive strategy in 1042 consecutive patients. Circulation 2002; 105: 1412-1415.

16. Bogaty P, Boyer L, Simard S, Dauwe F, Dupuis R, Verret $B$, et al. Clinical utility of C-reactive protein measured at admission, hospital discharge, and 1 month later to predict outcome in patients with acute coronary disease. The RISCA (recurrence and inflammation in the acute coronary syndromes) study. J Am Coll Cardiol 2008; 51: 2339-2346.

17. Ridker PM, Danielson E, Fonseca FA, Genest J, Gotto AM $\mathrm{Jr}$, Kastelein JJ, et al. Rosuvastatin to prevent vascular events in men and women with elevated C-reactive protein. 
N Engl J Med 2008; 359: 2195-2207.

18. Smith SC Jr, Dove JT, Jacobs AK, Kennedy JW, Kereiakes D, Kern MJ, et al. ACC/AHA guidelines for percutaneous coronary intervention (revision of the 1993 PTCA guidelines)executive summary: a report of the American College of Cardiology/American Heart Association Task Force on Practice Guidelines (Committee to revise the 1993 guidelines for percutaneous transluminal coronary angioplasty) endorsed by the Society for Cardiac Angiography and Interventions. Circulation 2001; 103: 3019-3041.

19. Antman EM, Cohen M, Bernink PJ, McCabe $\mathrm{CH}$, Horacek T, Papuchis G, et al. The TIMI risk score for unstable angina/ non-ST elevation MI: A method for prognostication and therapeutic decision making. JAMA 2000; 284: 835-842.

20. Packard RR, Libby P. Inflammation in atherosclerosis: from vascular biology to biomarker discovery and risk prediction. Clin Chem 2008; 54: 24-38.

21. Liuzzo G, Biasucci LM, Gallimore JR, Grillo RL, Rebuzzi AG, Pepys MB, et al. The prognostic value of C-reactive protein and serum amyloid a protein in severe unstable angina. $N$ Engl J Med 1994; 331: 417-424.

22. James SK, Armstrong P, Barnathan E, Califf R, Lindahl B, Siegbahn A, et al. Troponin and C-reactive protein have different relations to subsequent mortality and myocardial infarction after acute coronary syndrome: a GUSTO-IV substudy. J Am Coll Cardiol 2003; 41: 916-924.

23. Toss H, Lindahl B, Siegbahn A, Wallentin L. Prognostic influence of increased fibrinogen and C-reactive protein levels in unstable coronary artery disease. FRISC Study Group. Fragmin during Instability in Coronary Artery Disease. Circulation 1997; 96: 4204-4210.

24. Lindahl B, Toss H, Siegbahn A, Venge P, Wallentin L. Markers of myocardial damage and inflammation in relation to long-term mortality in unstable coronary artery disease. FRISC Study Group. Fragmin during Instability in Coronary Artery Disease. N Engl J Med 2000; 343: 1139-1147.

25. Suleiman M, Khatib R, Agmon Y, Mahamid R, Boulos M, Kapeliovich $\mathrm{M}$, et al. Early inflammation and risk of longterm development of heart failure and mortality in survivors of acute myocardial infarction predictive role of C-reactive protein. J Am Coll Cardiol 2006; 47: 962-968.

26. Bodi V, Sanchis J, Llacer A, Facila L, Nunez J, Bertomeu V, et al. Risk stratification in non-ST elevation acute coronary syndromes: predictive power of troponin I, C-reactive protein, fibrinogen and homocysteine. Int J Cardiol 2005; 98: 277-283.

27. Heeschen C, Hamm CW, Bruemmer J, Simoons ML. Predictive value of $\mathrm{C}$-reactive protein and troponin $\mathrm{T}$ in patients with unstable angina: a comparative analysis. CAPTURE Investigators. Chimeric c7E3 AntiPlatelet Therapy in Unstable angina REfractory to standard treatment trial. $\mathrm{J} \mathrm{Am}$ Coll Cardiol 2000; 35: 1535-1542.

28. de Winter RJ, Bholasingh R, Lijmer JG, Koster RW, Gorgels JP, Schouten Y, et al. Independent prognostic value of C-reactive protein and troponin I in patients with unstable angina or non-Q-wave myocardial infarction. Cardiovasc Res 1999; 42: 240-245.

29. Scirica BM, Morrow DA, Cannon CP, de Lemos JA, Murphy $\mathrm{S}$, Sabatine MS, et al. Clinical application of C-reactive protein across the spectrum of acute coronary syndromes. Clin Chem 2007; 53: 1800-1807.

30. Ridker PM, Cushman M, Stampfer MJ, Tracy RP, Hennekens $\mathrm{CH}$. Inflammation, aspirin, and the risk of cardiovascular disease in apparently healthy men. N Engl J Med 1997; 336: 973-979. 